\section{The carbon footprint of cataract surgery}

DS Morris ${ }^{1}$, T Wright ${ }^{2}$, JEA Somner ${ }^{3}$ and A Connor ${ }^{4}$

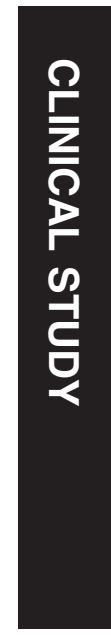

\begin{abstract}
Background Climate change is predicted to be one of the largest global health threats of the 21st century. Health care itself is a large contributor to carbon emissions. Determining the carbon footprint of specific health care activities such as cataract surgery allows the assessment of associated emissions and identifies opportunities for reduction.

Aim To assess the carbon footprint of a cataract pathway in a British teaching hospital. Methods This was a component analysis study for one patient having first eye cataract surgery in the University Hospital of Wales, Cardiff. Activity data was collected from three sectors, building and energy use, travel and procurement. Published emissions factors were applied to this data to provide figures in carbon dioxide equivalents $\left(\mathrm{CO}_{2} \mathrm{eq}\right)$.
\end{abstract}

Results The carbon footprint for one cataract operation was $181.8 \mathrm{~kg} \mathrm{CO}$ eq. On the basis that 2230 patients were treated for cataracts during 2011 in Cardiff, this has an associated carbon footprint of 405.4 tonnes $\mathrm{CO}_{2}$ eq. Building and energy use was estimated to account for $\mathbf{3 6 . 1 \%}$ of overall emissions, travel $10.1 \%$ and procurement $53.8 \%$, with medical equipment accounting for the most emissions at $32.6 \%$. Conclusions This is the first published carbon footprint of cataract surgery and acts as a benchmark for other studies as well as identifying areas for emissions reduction. Within the procurement sector, dialogue with industry is important to reduce the overall carbon footprint. Sustainability should be considered when cataract pathways are designed as there is potential for reduction in all sectors with the possible side effects of saving costs and improving patient care. Eye (2013) 27, 495-501; doi:10.1038/eye.2013.9; published online 22 February 2013

Keywords: Cataract; carbon footprint; sustainability; environment
Introduction

Climate change presents a major threat to global health in the 21st century. ${ }^{1}$ The World Health Organisation has predicted escalating health problems as a result of increases in natural disasters, food and water insecurity, and alterations in the nature and spread of infectious diseases. ${ }^{2}$ Resulting population migration will ensure that these effects impact globally.

It is now appreciated that human activities are driving climate change ${ }^{3}$ and that the very provision of health care represents one such activity. The carbon footprint of the National Health Service (NHS) in England is estimated at 20 million tonnes of greenhouse gases (GHGs) per annum and accounts for $25 \%$ of all public sector emissions in the United Kingdom. ${ }^{4}$ Therefore, health care professionals should not only advocate for global strategies to address climate change but should also seek to reduce the emissions attributable to their own medical establishments and practices. Although NHS emissions are now falling, the challenging targets presented by the NHS Carbon Reduction Strategy ${ }^{5}$ can only be met by first fully understanding the GHG emissions associated with the delivery of individual aspects of health care.

The term 'carbon footprint' has been used ubiquitously in both public debate and the scientific literature. Broadly speaking, it has been used to refer to an assessment of the gaseous emissions resulting from the full life cycle of a product or process, with particular attention given to those emissions considered to be of relevance to climate change. Carbon footprinting studies with varying methodological approaches and complexity are now being reported within the medical literature. $^{6-13}$ The importance of sustainability within the delivery of ophthalmic care has been considered previously, ${ }^{14,15}$ and the emissions attributable to small incision cataract surgery
${ }^{1}$ Cardiff Eye Unit, University Hospital of Wales, Cardiff, UK

${ }^{2}$ University of Cardiff Medical School, Cardiff, UK

${ }^{3}$ Vision and Eye Research Unit, Anglia Ruskin University, Cambridge, UK

${ }^{4}$ Department of Renal Medicine, South West Transplant Centre, Derriford Hospital, Devon, UK

Correspondence: University Hospital of Wales, Heath Park, Cardiff CF14 4XW, UK. Tel: +44 (0)2920 742083; Fax: +44 (0)2920 748240

E-mail: dsm@doctors.org.uk

Received: 12 July 2012 Accepted in revised form: 4 January 2013 Published online: 22 February 2013 DS Morris, Cardiff Eye Unit, 
have been argued to be smaller than those arising from phacoemulsification. ${ }^{16}$

Cataract surgery is a commonly performed surgical procedure within the NHS in England with over 300000 operations undertaken annually making it an ideal target for reducing emissions. ${ }^{17}$ The aims of this study were to determine the magnitude of the GHG emissions attributable to cataract surgery (at both individual patient and local service levels) and to identify opportunities for carbon reduction strategies.

\section{Materials and methods}

\section{Emissions terminology}

The Kyoto Protocol identifies six gases with global warming potential, although only three are commonly reported (carbon dioxide $\left(\mathrm{CO}_{2}\right)$, methane, and nitrous oxide). ${ }^{18} \mathrm{CO}_{2}$ is most commonly used as the reference gas, with the emissions of the other gases being expressed in the units of $\mathrm{CO}_{2}$ equivalents $\left(\mathrm{CO}_{2} \mathrm{eq}\right)$.

\section{Approach}

This was a component analysis study including both direct and indirect GHG emissions. Activity data attributable to an individual patient undergoing first eye cataract surgery were collected from the point of referral to the point of discharge at the University Hospital Wales, Cardiff. The cataract pathway is described in Figure 1. Data were collected for the sectors of energy use, travel, and procurement. The data were physical in nature for the energy and travel sectors and economic in nature for the procurement sector. These data were subsequently multiplied to determine the emissions attributable to the 2230 patients operated on in one year ending 1 January 2012.

Established emissions factors were applied to reconcile the activity data from the different sources to a single unit of measurement for GHG emissions $\left(\mathrm{CO}_{2} \mathrm{eq}\right)$. This report adheres to the principles and definitions defined within the Publicly Available Specification for the measurement of GHG emissions from goods and services (PAS2050). ${ }^{19}$

Emissions have been calculated on a consumption basis, and are the sum of three primary sectors: direct emissions from building energy use, direct emissions from the travel of patients and staff, and indirect procurement emissions. Procurement emissions can be defined as the embodied emissions associated with the production, consumption and disposal of all goods and services either consumed within the cataract pathway or arising in the industrial supply and disposal chains.
Referral from Optometrist or GP (paper-based) which is vetted. The patient is sent an appointment and hospital notes are created

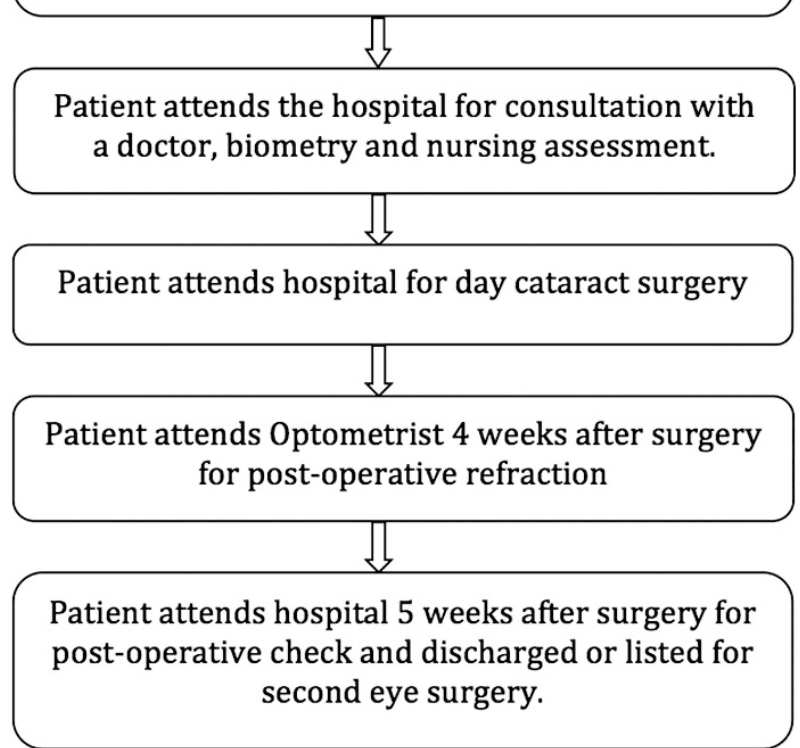

Figure 1 The cataract pathway followed by patients in the University Hospital of Wales, Cardiff.

\section{Assumptions and data sources}

There is a need to make a number of informed assumptions within any carbon footprinting methodology. The context of those assumptions, and the sources of data where considered important or unusual, are outlined here.

Building energy use Building energy use calculated from data submitted by the hospital to the National Estates Return Information Collection database during 2011 and is based upon the proportion of floor space required by the Ophthalmology Service to deliver the components of the cataract service (including outpatient care and day case surgery) and the proportion of time for which these areas are in use for this purpose. In the absence of publically available information, and in keeping with previous studies, ${ }^{6}$ it was assumed that building energy use within the operating theatres and recovery areas was twice that of mean energy use for a given floor space within the hospital.

Travel data 'Travel' is defined as the movement of staff and patients participating in the cataract pathway. Travel data, including departure location and mode of travel, were derived from questionnaires. A snapshot of staff travel behaviour patterns was ascertained from asking all the staff in theatre over 2 days how they had travelled to 
work. Questionnaires were distributed to 47 consecutive patients in the pre-operative area over a 2-week period and none of those asked declined to complete the questionnaire. Data from these patient questionnaires was analysed as they were being completed and the results were similar after 40 questionnaires as after 30 questionnaires so it was felt that 47 patients was representative of Cardiff cataract patients.

Distances were determined using GoogleMaps (http://maps.google.co.uk). It was assumed that each patient made three return journeys (assessment, surgery and follow-up) with a single relative undertaking the same mode of transport. It was assumed that an outpatient clinic required five staff members, and that a theatre list required ten staff members, to deliver care to 12 patients. The emissions attributable to an individual patient were apportioned accordingly.

Procurement data Economic procurement activity data were collected for pharmaceuticals, medical equipment, information technology, food and drink, and stationery. Physical data were collected regarding the weight of linen used by a single patient and associated theatre staff (apportioned on a per patient basis). Assumptions were made regarding the transport of the linen to the off-site laundry service and the energy requirements for the washing and drying of the laundry. Economic data relating to information technology were derived from the current financial cost of the hardware presently used to deliver the service and assumptions regarding its rate of replacement. Economic data relating to the use of paper and ink was estimated from determination of the amount of paper used during a patient's journey through the cataract pathway and assumptions regarding the amount of ink required to produce the proformas and the financial cost of the paper and ink.

Waste from outpatient appointments was considered to be negligible. Physical activity (weight and constituent material) data were collected for waste arising from the surgical treatment and apportioned to the domestic and clinical waste streams. It was assumed that all clinical waste underwent incineration and that all domestic waste was sent to landfill. At the time of data collection, no waste recycling was undertaken.

\section{Boundary setting}

Inclusions The emissions arising from the primary sectors (building energy use, travel, and procurement) were included in this study, and considered from the perspective of the impact of every identified staff member and patient. The emissions attributable to the travel of staff and patients have been included to maintain consistency with previous studies undertaken within the health care setting, ${ }^{6-8}$ including the NHS England Carbon Footprinting Study, although PAS2050 would suggest the exclusion of those emissions associated with the travel of employees and consumers. ${ }^{19}$

Exclusions To maintain consistency with PAS2050, ${ }^{19}$ the following sources of GHG emissions were excluded from the analysis: buildings and construction; sterilisation procedures; human inputs into processes; the capital cost of machinery used repeatedly; food and beverages for staff; scientific research; staff training; business services; and immaterial emissions sources (those anticipated to be $<1 \%$ of the total emissions). Second eye surgery was not included.

The use of surgical equipment, in the form of surgical instruments and machinery, is fundamental to cataract surgery. The manufacture of this machinery requires energy and results in GHG emissions. To maintain consistency with PAS2050, the GHG emissions arising from the production of capital goods used in the life cycle of the service have been excluded from the assessment of the GHG emissions of the service. ${ }^{19}$ However, emissions related to disposable consumables and pharmaceuticals used within or alongside this machinery, and the energy consumed by such machinery, are included. The emissions attributable to biometric investigations were also excluded as they were likely to be minimal.

\section{Emissions factors}

The emissions factors used in this study are reported in Table 1. The methodology applied within this study assigns the carbon embedded within the items of medical equipment, pharmaceuticals, stationery, and other procured goods to the procurement emissions. The 'end of life' emissions have therefore been calculated using the Department for Environment, Food and Rural Affairs (DEFRA) emissions factors for waste-treatment processes. ${ }^{20}$ As the DEFRA emissions factors for the incineration of different materials do not account for the incineration of clinical waste, which must be undertaken at higher temperatures and may therefore result in higher emissions, the highest available emissions factor for incineration has been applied to each of the constituents undergoing this form of disposal.

\section{Results}

The carbon footprint of a single patient undergoing first eye cataract surgery in Cardiff was $181.8 \mathrm{~kg} \mathrm{CO}$ eq. The contributions of the primary sectors are shown in Figure 2: building and energy use, travel and 
Table 1 The emissions factors applied to (a) building energy use activity data; (b) staff and patient travel activity data; (c) procurement activity data; (d) waste collection, treatment, and disposal activity data

\begin{tabular}{ll}
\hline $\begin{array}{l}\text { (a) Source of } \\
\text { energy }\end{array}$ & $\begin{array}{l}\text { Emissions factor to convert } \\
\text { to } \mathrm{GHG} \text { emissions }(\mathrm{kg} \\
\left.\mathrm{CO}_{2} \text { eq per } \mathrm{kWh}\right)^{a}\end{array}$ \\
\hline Electricity & \multicolumn{1}{c}{0.59368} \\
$\begin{array}{l}\text { (b) Mode of } \\
\text { transport }\end{array}$ & $\begin{array}{l}\text { Emissions factor to convert } \\
\text { to } \mathrm{GHG} \text { emissions }(\mathrm{kg} \\
\left.\mathrm{CO}_{2} \text { eq per } \mathrm{km}\right)^{a}\end{array}$ \\
\hline
\end{tabular}

\begin{tabular}{ll}
\hline $\begin{array}{l}\text { Active travel } \\
\text { (walking, }\end{array}$ & 0.0 \\
cycling) & \\
Car & \\
Bus & 0.24156 \\
Train & 0.17710 \\
Articulated & 0.06464 \\
& 1.40325
\end{tabular}

HGV

(c) Procurement Emissions factor to convert subsector to GHG emissions

Pharmaceuticals $0.59 \mathrm{~kg} \mathrm{CO}_{2}$ eq per pound ${ }^{\mathrm{a}}$ Medical $\quad 0.54 \mathrm{~kg} \mathrm{CO}_{2}$ eq per pound ${ }^{\mathrm{a}}$ equipment

Paper and ink $\quad 0.77 \mathrm{~kg} \mathrm{CO}_{2}$ eq per pound paper $^{\mathrm{a}}$ $0.63 \mathrm{~kg} \mathrm{CO}$ eq per pound ink $^{\mathrm{a}}$

Food Emissions used were for individual food and beverages ${ }^{\mathrm{b}}$

Information $\quad 0.76 \mathrm{~kg} \mathrm{CO}_{2}$ eq per pound ${ }^{\mathrm{a}}$ technology

$\begin{array}{lll}\text { (d) Waste } & \text { Waste } & \mathrm{kg} \mathrm{CO}_{2} \text { eq emitted } \\ \text { disposal method } & \text { constituent } & \begin{array}{l}\text { per tonne of waste } \\ \text { constituent }\end{array}\end{array}$

\begin{tabular}{llr}
\hline Incineration & All & 1833 \\
Landfill & Paper & 580 \\
& Plastic & 34 \\
\hline
\end{tabular}

${ }^{a}$ Emissions factors from DEFRA. ${ }^{20}$

${ }^{b}$ Emissions factors from National Statistics of Environmental Accounts. ${ }^{4}$

procurement contributed $65.7(36.1 \%), 18.3(10.1 \%)$, and $97.8(53.8 \%) \mathrm{kg} \mathrm{CO}_{2} \mathrm{eq}$, respectively (Table 2).

Extrapolating from this figure, on the basis that 2230 patients had cataract surgery during 2011 in Cardiff, the annual carbon footprint of the Cardiff cataract pathway in 2011 was $405392 \mathrm{~kg} \mathrm{CO}$ eq (405 tonnes $\mathrm{CO}_{2} \mathrm{eq}$ ).

\section{Discussion}

This is the first study to determine the direct and indirect GHG emissions attributable to the delivery of cataract

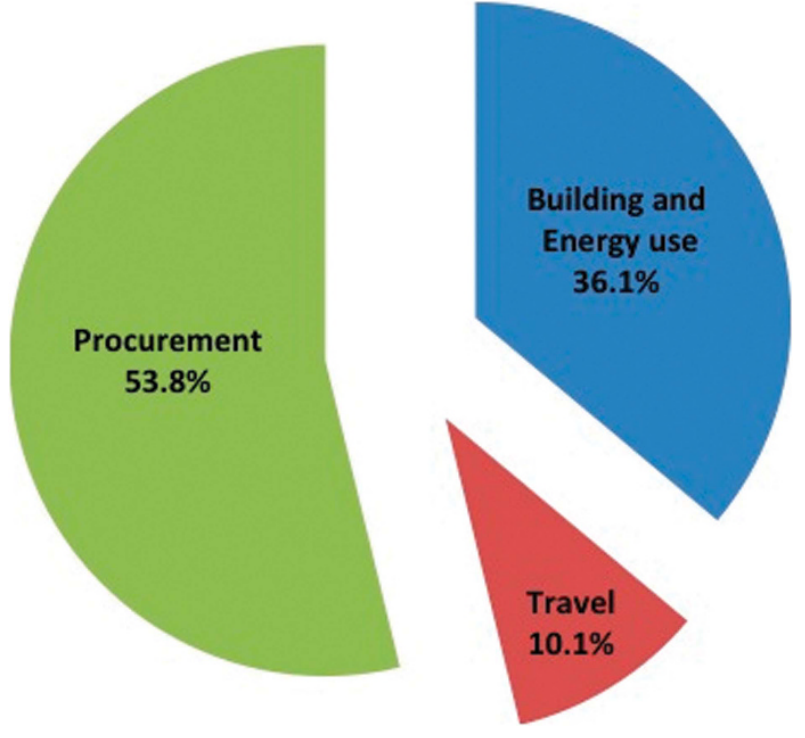

Figure 2 The carbon footprint of a patient undergoing first eye cataract surgery divided into primary sectors of GHG emissions.

Table 2 The GHG emissions attributable to an individual patient undergoing first eye cataract surgery

\begin{tabular}{|c|c|c|c|}
\hline Sector & Subsector & $\begin{array}{l}\mathrm{GHG} \\
\text { emissions ( } \mathrm{kg} \\
\left.\mathrm{CO}_{2} \mathrm{eq}\right)\end{array}$ & $\begin{array}{l}\text { Percentage of total } \\
\text { GHG emissions }\end{array}$ \\
\hline $\begin{array}{l}\text { Building } \\
\text { energy use }\end{array}$ & $\begin{array}{l}\text { Total building } \\
\text { energy use }\end{array}$ & 65.7 & $36.1 \%$ \\
\hline \multirow[t]{3}{*}{ Travel } & $\begin{array}{l}\text { Staff } \\
\text { commuting }\end{array}$ & 5.5 & $3.0 \%$ \\
\hline & Patient travel & 12.8 & $7.0 \%$ \\
\hline & Total travel & 18.3 & $10.1 \%$ \\
\hline \multirow[t]{9}{*}{ Procurement } & Pharmaceuticals & 32.7 & $18.0 \%$ \\
\hline & $\begin{array}{l}\text { Medical } \\
\text { equipment }\end{array}$ & 59.2 & $32.6 \%$ \\
\hline & Paper and ink & 0.9 & $0.5 \%$ \\
\hline & Food & 0.1 & $0.0 \%$ \\
\hline & $\begin{array}{l}\text { Laundry } \\
\text { services }\end{array}$ & 0.9 & $0.5 \%$ \\
\hline & $\begin{array}{l}\text { Information } \\
\text { technology }\end{array}$ & 0.4 & $0.2 \%$ \\
\hline & Water & 0.2 & $0.1 \%$ \\
\hline & Waste & 3.4 & $1.9 \%$ \\
\hline & $\begin{array}{l}\text { Total } \\
\text { procurement }\end{array}$ & 97.8 & $53.8 \%$ \\
\hline $\begin{array}{l}\text { Total per } \\
\text { patient }\end{array}$ & & $\begin{array}{l}181.8 \mathrm{~kg} \\
\mathrm{CO}_{2} \mathrm{eq}\end{array}$ & $100 \%$ \\
\hline
\end{tabular}

surgery. To provide context for this annual figure of 405 tonnes $\mathrm{CO}_{2} \mathrm{eq}$ for the Cardiff cataract pathway, the average carbon footprint of a UK resident is generally estimated at about 10 tonnes $\mathrm{CO}_{2}$ eq per year and a flight to New York from London generates between one and 
two tonnes of $\mathrm{CO}_{2} \mathrm{eq}$ per passenger. Extrapolating from our results, and assuming cataract services share similar carbon intensities nationally, we estimate the carbon burden of the 343782 lens extractions undertaken in 2011 in England ${ }^{17}$ to be around 63000 tonnes of $\mathrm{CO}_{2} \mathrm{eq}$.

While the magnitude of the emissions attributable to cataract surgery supports the need to address the problem, it is the origin of these emissions that offer an insight into the opportunities for carbon reduction. The procurement sector represents the major source of emissions (53.8\%) within the cataract pathway. Within this sector, the majority of emissions arise within the supply chains for medical equipment $(32.6 \%)$ and pharmaceuticals (18.0\%). This finding is in keeping with the results of the few published carbon footprinting studies undertaken within the health care setting to have included both direct and indirect emissions. ${ }^{4,6,7,10}$ The message is becoming increasingly clear: While carbon reduction strategies outside of the health care sector often focus upon the emissions arising from building energy use and travel, such strategies, although valuable, will prove insufficient to meet the targets set by the NHS Carbon Reduction Strategy. ${ }^{5}$ Instead, attempts to reduce GHG emissions arising within the health care setting must also target procurement emissions by, for example, working with industry partners to achieve carbon reduction.

The emissions attributable to the procurement of medical equipment are almost double those arising from pharmaceuticals - a finding that is not unexpected given the surgical nature of the treatment. However, the emissions associated with waste management represent a smaller contribution $(1.88 \%)$ than has been reported for other health care services and treatments. ${ }^{5-7}$ The introduction of strategies to recycle components of the waste generated by the cataract pathway is therefore likely to have a limited impact upon the overall carbon footprint. However, such strategies remain desirable; not only will the introduction of recycling reinforce staff awareness of the importance of sustainability within health care but also such measures are likely to be costeffective.

The subsectors resulting in the highest emissions should not become the sole focus of carbon reduction strategies in the same way that the burden of a particular disease should not determine the extent of the medical resources allocated to it in a health care system with limited financial resources; ${ }^{21}$ cost-effective carbon reduction strategies should be prioritised irrespective of the sector. Indeed, although the contribution of paper and ink to the overall emissions of the pathway is relatively minor, the introduction of a paperless system might not only reduce emissions but also make the pathway safer and more efficient, therefore being a benefit to patients and clinicians as well. ${ }^{22}$

Many of the opportunities to reduce procurement emissions will require dialogue between clinicians and the ophthalmology industry. For example, the intraocular lens used in the Cardiff cataract pathway weighs less than $1 \mathrm{~g}$, whereas the associated paper and plastic packaging weighs $64 \mathrm{~g}$, including a 70-page booklet in 11 different languages. Although packaging is governed by strict legislation, it may be possible to work in partnership with pharmaceutical companies who already have carbon reduction strategies. Furthermore, the incorporation of sustainability criteria into the contracts tendered by ophthalmology services might be anticipated to drive down the emissions arising within the supply chains.

The contribution of building energy use $(36.1 \%)$ to the overall emissions within the provision cataract surgery is greater than its contribution to health care in general $(22 \%),{ }^{5}$ perhaps reflecting the increased energy consumption of surgical theatres, and may prove challenging to modify in the short to medium term. However, changes to the cataract pathway itself may allow reductions in the travel emissions. Within the Cardiff cataract service, patient travel emissions (which contribute $7 \%$ of the emissions) might be reduced by providing follow-up locally through the optometry services, as is undertaken in other regions of the United Kingdom.

Comparison of the results of this study with the emissions arising from other surgical specialties is not possible due to the absence of published studies: a literature search undertaken through Pubmed, for articles published in English since 1 January 2000, restricting the search term (('sustainable' or 'sustainability' or 'carbon footprint' or 'greenhouse gas' or 'climate change') and 'surgery') to titles and abstracts, returned 198 articles of which only 3 were considered relevant. ${ }^{12,16,23}$

The uncertainty profiles of the two main approaches to carbon footprinting, component analysis and inputoutput assessments, differ and the use of one of these approaches in isolation can present difficulties when evaluating the magnitude of uncertainty of a study. The study reported here involves a component analysis approach only, and therefore the extent of any truncation error (the result of the exclusion of components of the service or product within the assessment) cannot easily be estimated as it was not feasible to undertake a concurrent input-output approach due to the nature of the service being assessed.

A second limitation relates to the variation in the activity data for the different sectors (particularly patient travel) that might exist between regions or internationally, particularly where the patient pathway 
differs from that used in Cardiff. Caution must therefore be exercised when translating the results reported here to other cataract care pathways elsewhere.

Finally, the emissions arising within the supply chains of the medical equipment and pharmaceuticals contribute $50.6 \%$ of the overall emissions arising from the care of patients requiring cataract surgery. However, the emissions factors available for these subsectors are not specific to the products used in cataract surgery, or indeed even to those used commonly within the field of ophthalmology, and therefore introduce a degree of error to the results that is difficult to quantify. The determination of more specific emissions factors is required to underpin the development of carbon footprinting methodologies and future studies across all specialties of medicine. ${ }^{24}$

This is the first carbon footprinting study to report the direct and indirect emissions arising from the delivery of a cataract service. Hopefully it will act as a benchmark and encourage others to perform similar assessments of their own service. The magnitude of these emissions demands the development of carbon reduction strategies, while the breakdown of their origins highlights the opportunities for the implementation of such strategies. The reduction of emissions arising within the supply chains should be prioritised. The contributions of the procurement subsectors differ from those of other comparable studies, illustrating the importance of undertaking footprinting studies within different specialties and treatments.

\section{Summary}

What was known before

- Climate change is now a fact. Human activities are driving climate change and health care provision is one of those activities.

- The carbon footprint of the National Health Service in England is estimated at 20 million tonnes of greenhouse gases per annum.

- Cataract surgery is one of the most common elective procedures but its carbon footprint is not yet quantified.

What this study adds

- This study has defined the carbon footprint of cataract surgery at $181.8 \mathrm{~kg} \mathrm{CO}_{2} \mathrm{eq}$ for first eye surgery in a British hospital.

- Using this component analysis study, procurement, and especially medical equipment, was found to cause most emissions.

- This study should set the benchmark for other studies and changing practice.

\section{Conflict of interest}

The authors declare no conflict of interest.

\section{Acknowledgements}

We thank the patients and staff at the University Hospital of Wales for their patience and cooperation with this project.

\section{References}

1 Costello A, Abbas M, Allen A, Ball S, Bell S, Bellamy R et al. Managing the health effects of climate change: Lancet and University College London Institute for Global Health Commission. Lancet 2009; 373(9676): 1693-1733.

2 World Health Organisation. Global Health Risks: Mortality and burden of disease attributable to selected major risks, WHO Library Cataloguing-in-Publication Data 2009.

3 Intergovernmental Panel on Climate Change. 2007: Summary for Policymakers. In: Solomon S, Qin D, Manning M, Chen Z, Marquis M, Averyt KB, Tignor M, Miller HL (eds) Climate Change 2007: The Physical Science Basis. Contribution of Working Group I to the Fourth Assessment Report of the Intergovernmental Panel on Climate Change. Cambridge University Press: Cambridge, United Kingdom and New York, 2007.

4 NHS England. Carbon Emissions: Carbon Footprinting StudySustainable Development Commission: London, 2008.

5 NHS Sustainable Development Unit. Saving carbon, improving health. NHS Sustainable Development Unit, London, 2009.

6 Connor A, Lillywhite R, Cooke M. The carbon footprint of a renal service in the United Kingdom. QJM 2010; 103(12): 965-975.

7 Connor A, Lillywhite R, Cooke M. The carbon footprints of home and in-centre maintenance hemodialysis in the UK. Hemodial Int 2011; 15: 39-51.

8 Zander A, Niggebrugge A, Pencheon D, Lyratzopoulos G. Changes in travel-related carbon emissions associated with modernization of services for patients with acute myocardial infarction: a case study. J Public Health 2011; 33(2): 272-279.

9 McGain F, McAlister S, McGavin A, Story D. The financial and environmental costs of reusable and single-use plastic anaesthetic drug trays. Anaesth Intensive Care 2010; 38(3): 538-544.

10 Chung JW, Meltzer DO. Estimate of the carbon footprint of the US health care sector. JAMA 2009; 302(18): 1970-1972.

11 Somner JE, Stone N, Koukkoulli A, Scott KM, Field AR, Zygmunt J. Surgical scrubbing: can we clean up our carbon footprints by washing our hands? J Hosp Infect 2008; 70(3): 212-215

12 Gatenby PA. Modelling the carbon footprint of reflux control. Int J Surg 2011; 9(1): 72-74.

13 Wootton R, Tait A, Croft A. Environmental aspects of health care in the Grampian NHS region and the place of telehealth. J Telemed Telecare 2010; 16(4): 215-220.

14 Somner JE, Connor A, Benjamin L. Eyes, economics and the environment: should green issues drive changes in ophthalmic care?-yes. Eye 2010; 24(8): 1309-1311.

15 Lockington D, Dutton GN. Eyes, economics and the environment: should green issues drive changes in ophthalmic care?-no. Eye 2010; 24(8): 1312-1314.

16 Somner J, Scott K, Morris D, Gaskell A, Shepherd I. Ophthalmology carbon footprint: something to be considered? J Cataract Refract Surg 2009; 35(1): 202-203 
17 UK Hospital Episode Statistics. Headline figures 20102011The Health and Social Care Information Centre: London, 2011.

18 Reference Manual on Accounting of Emissions and Assigned Amount. United Nations Framework Convention on Climate Change. Kyoto Protocol 2008.

19 Specification for the assessment of the life cycle greenhouse gas emissions of goods and services. British Standards, DEFRA, Carbon Trust. PAS2050: London 2011.

20 Guidelines to DEFRA/ DECC's GHG Conversion Factors for Company Reporting DEFRA 2011.
21 Williams A. Calculating the global burden of disease: time for a strategic reappraisal? Health Econ 1999; 8: 1-8

22 Turley M, Porter C, Garrido T, Gerwig K, Young S, Radler L et al. Use of electronic health records can improve the health care industry's environmental footprint. Health Aff 2011; 30(5): 938-946.

23 Gilliam AD, Davidson B, Guest J. The carbon footprint of laparoscopic surgery: should we offset? Surg Endosc 2008; 22(2): 573

24 Connor A, O'Donoghue D. Sustainability: The seventh dimension of quality in health care. Hemodial Int 2012; 16(1): 2-5. 